\title{
Study on Fuzzy Self-Adaptive PID Control System of Biomass Boiler Drum Water ${ }^{*}$
}

\author{
Junran Jin ${ }^{1}$, Hengshuo Huang ${ }^{2}$, Junman Sun ${ }^{1}$, Yongchao Pang ${ }^{1}$ \\ ${ }^{1}$ College of Electric and Information Engineering, Zhengzhou University of Light Industry, Zhengzhou, China \\ ${ }^{2}$ Zhumadian Power Supply Company, Zhumadian, China \\ Email: Jinran226@163.com
}

Received February 2, 2013; revised March 7, 2013; accepted March 18, 2013

\begin{abstract}
The paper discusses the features of the Biomass Boiler drum water level. Conventional PID Control System can not reach a satisfaction result in nonlinearity and time different from Biomass Boiler Drum Water Control System. In this study, a kind of fuzzy self-adaptive PID controller is described and this controller is used in biomass boiler's drum water level control system. Using the simulink tool of MATLAB simulation software to simulate the fuzzy adaptive PID and conventional PID control system, the result of the comparison shows that the fuzzy self-adaptive PID has the strong anti-jamming, flexibility and adaptability as well as the higher control precision in Biomass Boiler Drum Water.
\end{abstract}

Keywords: Biomass Boiler; Fuzzy Adaptive PID; Fuzzy Control

\section{Introduction}

The biomass energy is the energy that can be transformed solar energy into chemical energy and stored in the organisms internal with the help of the green plant photosynthesis directly or indirectly. Modern biomass is seen as one of the most promising renewable energy sources in the near future. Using biomass to generate energy carries like heat, electricity and gaseous and liquid fuels can contribute significantly to the reduction of greenhouse gas emissions, as shown in many studies and project in most scenarios about potential development of energy and economic systems [1]. Biomass boiler can improve the utilization of biomass for centralized large-scale use of biomass energy, adopting advanced combustion technology to transform the biomass into the boiler fuel [2]. Development of biomass boiler technology can save coal and other fossil fuels which will help alleviate the energy crisis and meet the national energy saving policy.

In the biomass boiler combustion system, the boiler drum water level is an important parameter and it is a sign to measure whether boiler steaming-water system is balance. Maintaining the boiler drum water level in the specified range is a necessary condition and one of the important indexes for the boiler safe operation. If the water level is too low, the water of bubbles lessens at the same time the load largeness. The results are the vaporization speed is very fast and the change rate of water

$\overline{\text { *Supported by Foundation of Henan Educational Committee (2009B51 }}$ 0017). volume is also high. The boiler will explode if it isn't controlled in time [3]. If the water level is too high, it will influence the steam water separation. Then steam with water makes superheated fouling and destroys it. If steam with water is the energy of the turbine, superheated steam drops dramatically so that turbine blades are damaged and it causes the problems of safety and economy. So it is not allowed that the water level is too low or too high. Because many confounding factors, such as biomass fuels' humidity, density, type, as well as the change of boiler load are uncertain, time-varying, non-linear, biomass boiler combustion system is actually a fluctuation complex system, showing strong coupling, nonlinear, large inertia, time variation parameters and uncertainties. And thus it is very difficult to establish a precise mathematical model. Because the traditional PID control can not meet the control precision and the corresponding speed requirements, fuzzy adaptive PID control theory is a new theory combining traditional PID control and fuzzy logic, which does not require the exact mathematical model of controlled object and adapt to the fast, small overshoot, and the short transition. This control method is suitable for biomass boiler drum water level control system [4].

\section{The Design of Fuzzy Controller}

\subsection{The Control Difficulties of Biomass Boiler Drum Water Level}

Biomass boiler drum water level is important monitoring parameters in the boiler operation. It indirectly reflects 
the equilibrium relation between boiler steam load and water inflow. Keeping the right level of the steam pocket is the essential condition to ensure the safety of boiler and steam turbine. Because of the change of the steam load and the feeding water pressure, there is "false water level" phenomenon appearing in the boiler. In the operation, when steam load increases, evaporation is greater than the feed water. Water level rises rapidly. It caused by steam volume in the steam water mixture increasing rapidly. This phenomenon called "false liquid level". When the steam load increases sharply, the water level drops after rising for a while. When the steam load decreases sharply, the water level rises after dropping for a while. "False liquid level" phenomenon appears when this controlled variable is disturbance. If the feed water using single loop system which viewed water level as controlled variable, the adjuster will opposite the direction of the water flow and the direction of the change in load [5]. Consequently, it enlarges the imbalance between input flow and output flow.

Conventional PID control can't solve the "false liquid level" phenomenon well. However, if the fuzzy control arithmetic is put into the "false liquid level", the water level of steam boiler can be controlled well.

\subsection{The Composition of Fuzzy Self-Adjusting PID Controller}

Fuzzy self-adjusting PID controller is composed of adjustable PID controller and fuzzy controller. The core is fuzzy controller. It contains fuzzification, repository, fuzzy inference, defuzzification, and input/output quantification and so on. Fuzzy logic is a rule which can map a space-input to another space-output. In engineering application, fuzzy logic has the following characters: 1) Fuzzy logic is flexible; 2) Fuzzy logic is based on natural language, and the requirement for intensive reading of data is not very high; 3) Fuzzy logic can take full advantage of expert information; 4) Fuzzy logic is easy to combine with traditional control technique [6].

Fuzzy self-adjusting PID controller takes E (the error between feedback value and desired value of controlled station) and $\mathrm{E}_{\mathrm{c}}$ (error rate) as input. Using fuzzy reasoning method it adjusts the PID parameters $\left(\mathrm{K}_{\mathrm{p}}, \mathrm{K}_{\mathrm{i}}, \mathrm{K}_{\mathrm{d}}\right)$ which can meet the requirements of $\mathrm{E}$ and $\mathrm{E}_{\mathrm{c}}$ for PID parameter self-setting in different time. Change the PID parameters on line by using the fuzzy rules; these functions form the self-setting fuzzy PID controller. Its control system architecture is shown in Figure 1.

\subsection{Membership Function of Linguistic Variable}

According to the precision and control requirements, it is appropriate that 7 levels are usually selected. The range of fuzzy analects for input variable $\mathrm{E}, \mathrm{E}_{\mathrm{c}}$ is usually $[-3$, 3], which which is shown in Figure 2; the range of fuzzy

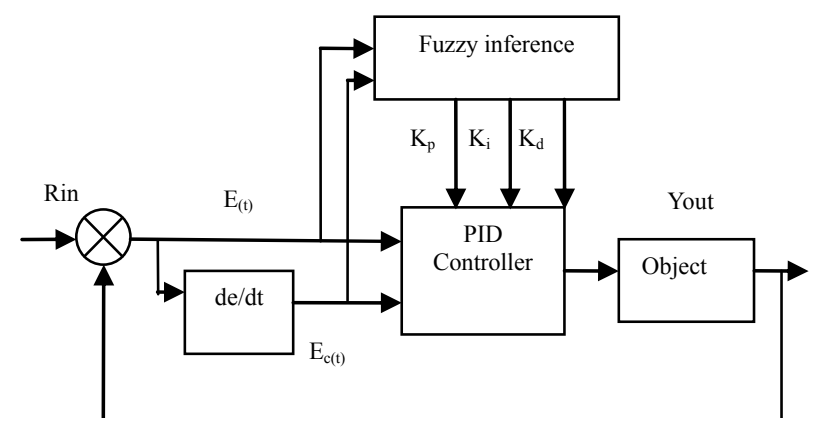

Figure 1. The structure of fuzzy self-adjusting PID controller.

analects for the output of $\mathrm{K}_{\mathrm{p}}$ is $[-0.3,0.3]$ and the range of fuzzy analects for the output of $\mathrm{K}_{\mathrm{d}}$ is $[-0.3,0.3]$, which are shown in Figure 3; the range of fuzzy analects for the output of $\mathrm{K}_{\mathrm{i}}$ is $[-0.06,0.06]$, which is shown in Figure 4. The analects linguistic values of input/output linguistic variable are PB, PM, PS, Z0, NS, NM, NB. The following figures are the membership function of linguistic variables' definition.

\subsection{The Control Rules of Fuzzy Controller}

The three parameters of PID arithmetic will influence stability, response speed, overshoot and steady precision of the system [7]. In the process operation system, the auto modification rules for $\mathrm{E}$ (different error), $\mathrm{E}_{\mathrm{c}}$ (error rate), $K_{p}, K_{i}$ and $K_{d}$ are following items.

1) When $E$ is relatively big, we should take the bigger $\mathrm{K}_{\mathrm{p}}$ and the smaller $\mathrm{K}_{\mathrm{d}}$ to make sure that the system has a good tracking performance. We should also strictly take an integral action to avoid the system has a larger overshoot. Usually take $\mathrm{K}_{\mathrm{i}}=0$;

2) When $E$ and $E_{c}$ is quite suitable, we should make the $K_{p}$ smaller to make sure the system has a smaller overshoot. On this occasion, we should take the suitable $\mathrm{K}_{\mathrm{i}}$ while $\mathrm{K}_{\mathrm{d}}$ has important influence on system;

3) When E is very small, we should take the bigger $K_{p}$ and the bigger $\mathrm{K}_{\mathrm{i}}$ to make sure that the system has a stable performance. We should also take a suitable $K_{d}$ which is based on $\mathrm{E}_{\mathrm{c}}$ to avoid the system oscillation appeared in set value. When $E_{c}$ is small, take a bigger $K_{d}$; When $E_{c}$ is big, take a smaller $K_{d}$. We make some control-rule figures in the following tables according to the setting principle and the simulation test.

It needs you to transform the output energy of fuzzy controller into accurate quantity after the design of control rules. Then the data can be sent to control actuator. The design realized the organization of fuzzy quantity by using of method of weighted mean [8]. The Tables 1-3 are showing the fuzzy control rules of $\mathrm{K}_{\mathrm{p}}$.In the online operation, it works out the deviation and the deviation rate in current time by constantly testing the output data of the system. Then fuzzifier them and get $\mathrm{E}, \mathrm{E}_{\mathrm{c}}$, you can get 
Table $1 . K_{\mathbf{p}}$ fuzzy control rules.

\begin{tabular}{cccccccc}
\hline \multirow{2}{*}{$\mathrm{E}_{\mathrm{c}}$} & \multicolumn{7}{c}{ E } \\
\cline { 2 - 7 } & NB & NM & NS & ZO & PS & PM & PB \\
\hline NB & PB & PB & PM & PM & PS & ZO & ZO \\
NM & PB & PB & PM & PS & PS & ZO & NS \\
NS & PM & PM & PM & PS & ZO & NS & NS \\
ZO & PM & PM & PS & ZO & NS & NM & NM \\
PS & PS & PS & ZO & NS & NS & NM & NM \\
PM & PS & ZO & NS & NM & NM & NM & NB \\
PB & ZO & ZO & NM & NM & NM & NB & NB \\
\hline
\end{tabular}

Table $2 . K_{\mathbf{i}}$ fuzzy control rules.

\begin{tabular}{|c|c|c|c|c|c|c|c|}
\hline \multirow{2}{*}{$\mathrm{E}_{\mathrm{c}}$} & \multicolumn{7}{|c|}{ E } \\
\hline & NB & $\mathrm{NM}$ & NS & $\mathrm{ZO}$ & PS & PM & PB \\
\hline NB & NB & NB & NM & NM & NS & $\mathrm{ZO}$ & $\mathrm{ZO}$ \\
\hline $\mathrm{NM}$ & NB & NB & NM & NS & NS & $\mathrm{ZO}$ & $\mathrm{ZO}$ \\
\hline NS & NB & $\mathrm{NM}$ & NS & NS & $\mathrm{ZO}$ & PS & PS \\
\hline $\mathrm{ZO}$ & $\mathrm{NM}$ & $\mathrm{NM}$ & NS & $\mathrm{ZO}$ & PS & $\mathrm{PM}$ & $\mathrm{PM}$ \\
\hline PS & $\mathrm{NM}$ & NS & $\mathrm{ZO}$ & PS & PS & PM & PB \\
\hline $\mathrm{PM}$ & $\mathrm{ZO}$ & $\mathrm{ZO}$ & PS & PS & $\mathrm{PM}$ & $\mathrm{PB}$ & $\mathrm{PB}$ \\
\hline PB & $\mathrm{ZO}$ & $\mathrm{ZO}$ & PS & PM & PM & $\mathrm{PB}$ & $\mathrm{PB}$ \\
\hline
\end{tabular}

Table $3 . K_{\mathbf{i}}$ fuzzy control rules.

\begin{tabular}{cccccccc}
\hline & & & \multicolumn{5}{c}{ E } \\
\cline { 2 - 7 } & NB & NM & NS & ZO & PS & PM & PB \\
\hline NB & PS & NS & NB & NB & NB & NM & PS \\
NM & PS & NS & NB & NM & NM & NS & ZO \\
NS & ZO & NS & NM & NM & NS & NS & ZO \\
ZO & ZO & NS & NS & NS & NS & NS & ZO \\
PS & ZO & ZO & ZO & ZO & ZO & ZO & ZO \\
PM & PB & NS & PS & PS & PS & PS & PB \\
PB & PB & PM & PM & PS & PS & PS & PB \\
\hline
\end{tabular}

the adjusted quantity of the three parameters through control rules. All these steps are the adjustments to the controller parameters.

\section{Simulation Research}

The model is constructed in the environment of Matlab/ Simulink, which is composed of fuzzy controller, PID control module, controlled member and input/output, using Simulink, Simulink extras, fuzzy logic and toolbox.

\subsection{The Editor of Fuzzy Controller}

In MATLAB, a new FIS file is made by the FIS editor to confirm the structure and membership of fuzzy controller. As shown in Figure 5.

Input the membership functions and fuzzy rule of E, 


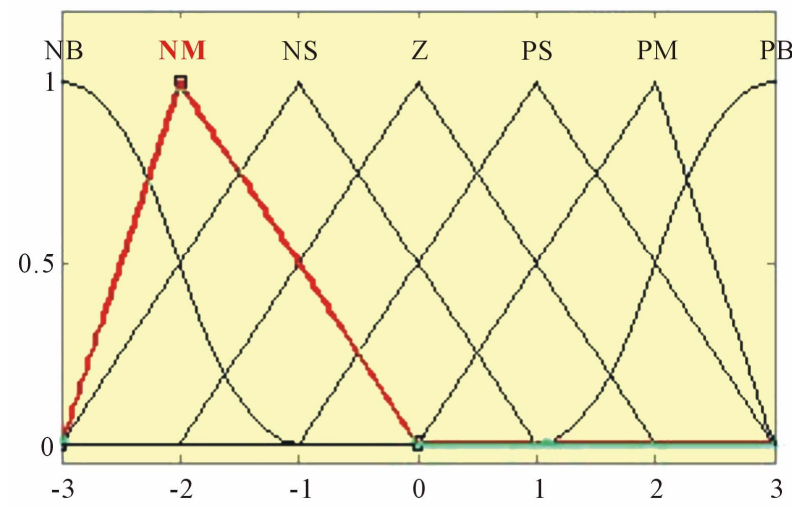

Figure 2. E, $\mathrm{E}_{\mathrm{c}}$ membership function curve.

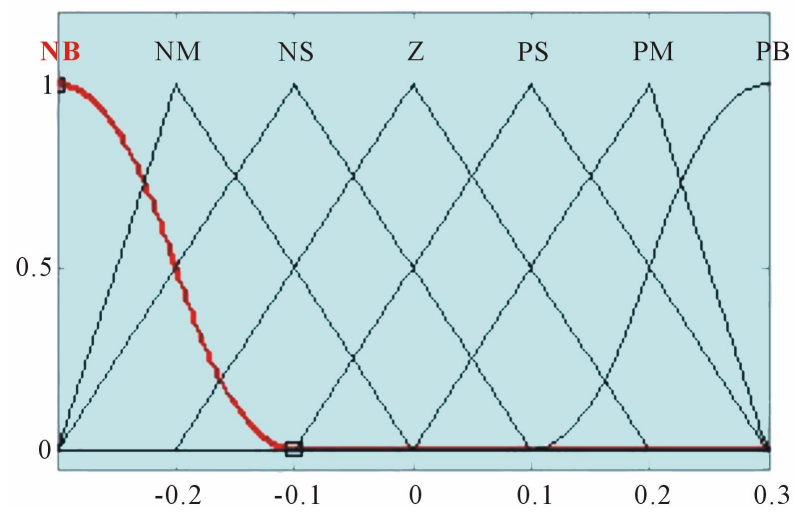

Figure 3. $K_{p}, K_{d}$ membership function curve.

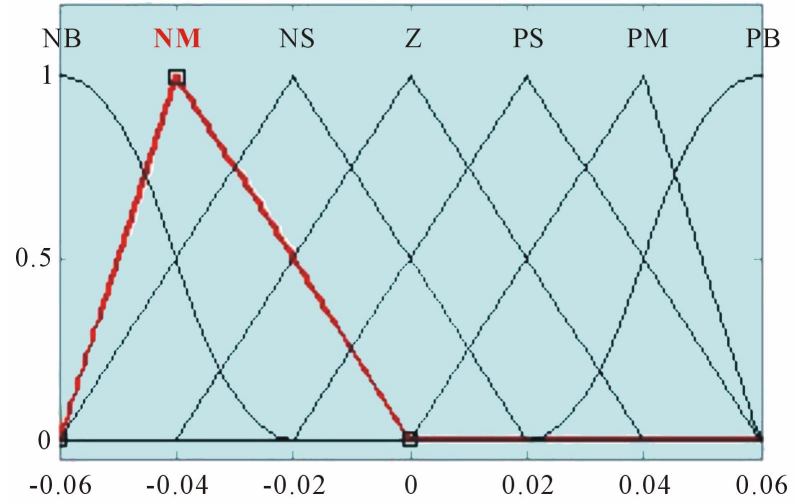

Figure 4. $K_{i}$ membership function curve.

$E_{c}, K_{p}, K_{i}, K_{d}$ in turns. And "and method" is regarded as min, "or method" as max, "implication" as min, "aggregation" as max and "defuzzification" as centroid. The file is saved and loaded into workspace when you want to simulate the module.

\subsection{The Simulation of Fuzzy Self-Adjusting PID Controller (Figure 6)}

Select a boiler drum as controlled object. And the transfer function of feeding water flow and water level is

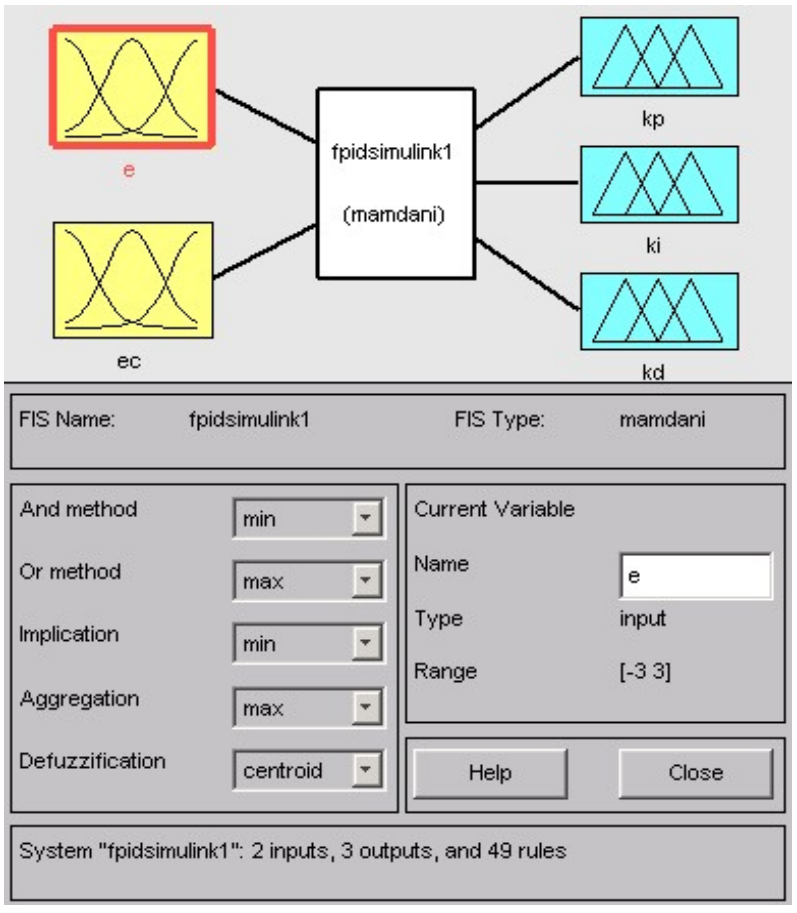

Figure 5. FIS editor window.

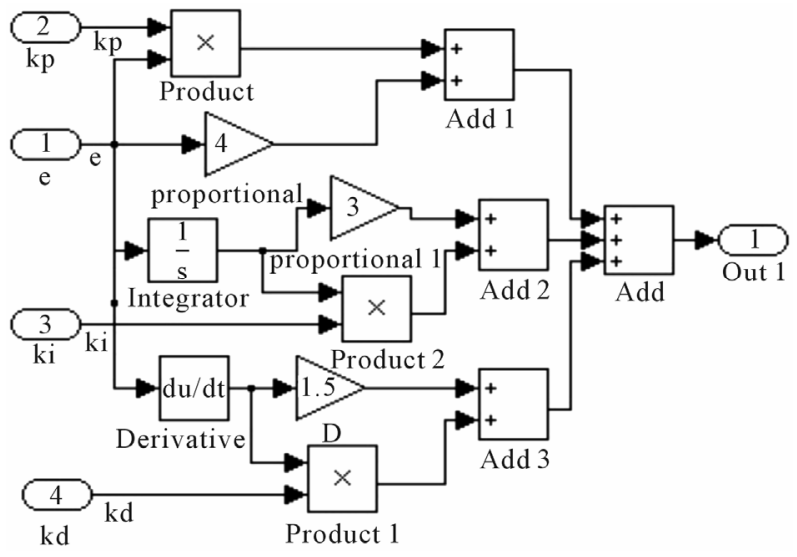

Figure 6. PID controlle rblock diagram.

$\mathrm{G}(\mathrm{s})=\frac{10}{2 \mathrm{~s}^{2}+3 \mathrm{~s}+1}$, justification factor $\mathrm{K}_{\mathrm{e}}=0.9, \mathrm{~K}_{\mathrm{ec}}=$ 0.1. Defuzzification factor $\mathrm{K}_{1}=3, \mathrm{~K}_{2}=1.2, \mathrm{~K}_{3}=0.01$, PID initial value $K_{p}=4, K_{i}=3, K_{d}=1.5$.

\section{Analysis of Simulation Results}

In this section, the step response simulations by using fuzzy PID control and PID control respectively. Furthermore, authors make some comparisons between them. The simulation results are shown by Figures 6-9.

It can be seen that the fuzzy adaptive PID controller makes the speed of response much quicker, the overshoot much smaller, and the oscillation time much shorter such that the states soon reach the level of stability than that of 


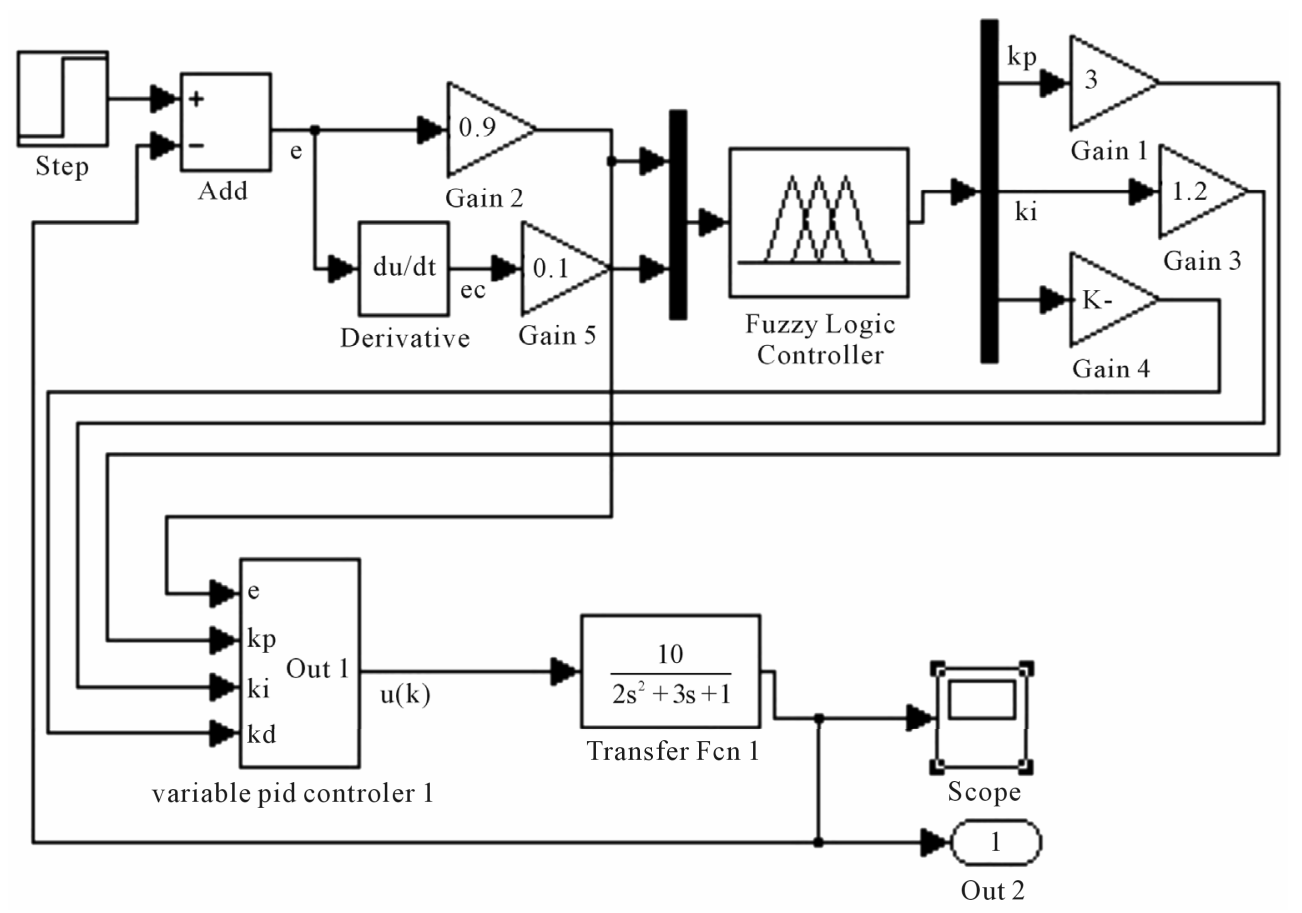

Figure 7. Fuzzy adaptive PID controlle rblock diagram.

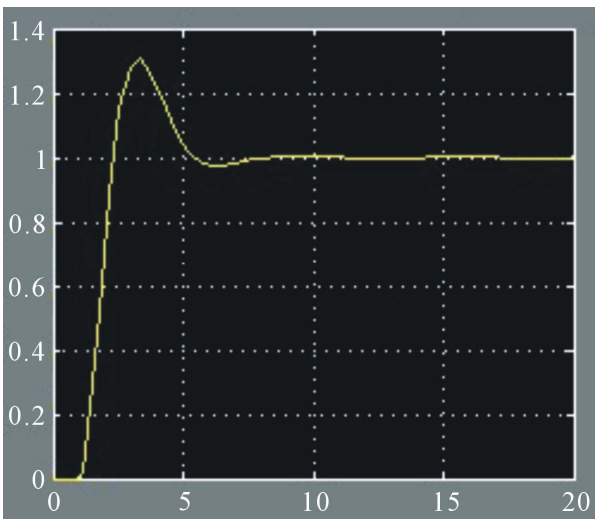

Figure 8. The simulation wave forms by using the PID control.

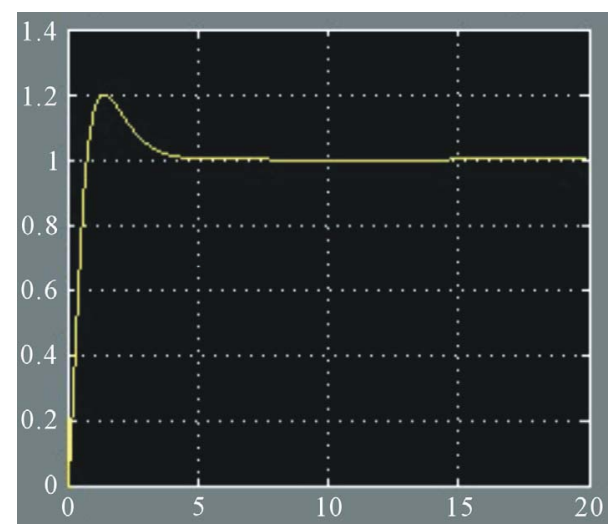

Figure 9. The simulation wave forms by using the fuzzy adaptive PID control. the PID controller. In a word, the fuzzy adaptive PID controller shows good dynamic and static performance indicators. The fuzzy adaptive PID control algorithm merges the advantages of the PID control and the fuzzy control, and it provides a good control method for the complex systems and the systems with higher demand dynamic process.

\section{REFERENCES}

[1] A. Demibas, "Biomass Resource Facilities And BioMass Conversion Processing for Fuels and Chemical," Energy Conversion and Management, Vol. 42, No. 11, 2001, pp. 1357-1378. doi:10.1016/S0196-8904(00)00137-0

[2] T. M. I. Mahlia, M. Z. Abdulmuin and T. M. I. Almsyah, "Dynamic Modeling and Simulation of a Palm Wastes Boiler," Energy, Vol. 28, No. 8, 2003, pp. 1235-1256.

[3] S. H. Zhu and Z. Li, "Study on Control of Water Level in Boiler Based on Fuzzy Self-Tuning PID," Journal of Shenyang Institute of Engineering (Natural Science), Vol. 6, 2010 .

[4] J. Li and D. Q. Wang, "Design of Fuzzy PID Controler and Its Simulation Based on MATLAB," Industrial Control Computer, Vol. 24, 2011.

[5] Q. E. Wu, J. M. Sun, J. F. Wang, et al., "Fuzzy Automata System with Application," Journal of Computation and Theoretical Nan Science, Vol. 7, No. 10, 2010, pp. 19111920. doi:10.1166/jetn.2010.1559

[6] J. M. Sun, Z. H. Xie, L. P. Li and G. J. Feng, "Simulation Research on Fuzzy Self-Adaptive PID Control 
Systerm of Biomass Boiler," Boiler Technology, Vol. 41, 2010.

[7] U. Moon and K. Y. Lee, "A Boiler-Turbine System Control Using a Fuzzy Auto-Regressive Moving Average Model," IEEE Transaction on Energy Conversion, Vol. 18,
2003, pp. 165-172.

[8] X. Chen, Y. J. Ding and J. Rong, "The Design and Simulation of Fuzzy PID Algorithm of Temperature of Boiler," Journal of YUEYANG Vocational Technical College, Vol. 26, 2011. 